\title{
Differences in epitope accessibility of p53 monoclonal antibodies suggest at least three conformations or states of protein binding of p53 protein in human tumor cell lines
}

\author{
Mary K. Danks ${ }^{1}$, David O. Whipple ${ }^{1}$, Christina R. McPake ${ }^{1}$, \\ Daiying $\mathrm{Lu}^{1}$ and Linda C. Harris ${ }^{1,2}$ \\ 1 Department of Molecular Pharmacology, St. Jude Children's Research \\ Hospital, Memphis, Tennessee 38101, USA \\ 2 corresponding author: Linda C. Harris, Department of Molecular \\ Pharmacology, St. Jude Children's Research Hospital, 332 N. Lauderdale, \\ Memphis, Tennessee 38105; tel: (901) 495-3440; fax: (901) 521-1668
}

Received 3.2.98; revised 27.3.98; accepted 8.5.98

Edited by D. Green

\begin{abstract}
The p53 tumor suppressor gene is deleted or mutated in over $50 \%$ of human tumors. Mutations frequently extend the halflife of the p53 protein; and a high level of nuclear p53 expression, detected by immunohistochemistry, has been used to predict the p53 status of tumors. We compared the sensitivity and reactivity of five frequently used, commercially available monoclonal antibodies (1801, D01, D07, BP53.12 and 421) in immunoblot and immunofluorescence assays, and found that results differed among the antibodies. Comparison of immunoblot analysis of denatured nuclear and cytoplasmic p53 protein were consistent with antibodies D01, D07 and BP53.12, each of which generated a strong specific signal in both cell fractions. However, in situ analysis demonstrated that although all antibodies recognized nuclear p53, only BP53.12 and 421 recognized p53 protein in the cytoplasm. In addition, 1801 produced a signal in p53-negative tumor cell lines. Differences in situ among the antibodies were probably due to the accessibility of their respective epitopes and suggested that nuclear and cytoplasmic p53 either have different three-dimensional conformations or are bound to different proteins. A third p53 protein conformation was also suggested by the observation that only two of the five antibodies (BP53.12 and D07) detected induced levels of p53 in situ following exposure to ionizing radiation. In summary, except for the fact that D07 does not recognize cytoplasmic p53 in situ, we found it to be the most specific, versatile, and reliable antibody. We conclude that the p53 antibody of choice depends upon the specific goal of a study and the method used to detect this protein.
\end{abstract}

Keywords: immunofluorescence; immunoblotting; p53; 1801; 421; DO1; D07; BP53.12

Abbreviations: wtp53, wild-type p53; mp53, mutant p53; BSA, bovine serum albumin; PBS, phosphate buffered saline

\section{Introduction}

The tumor suppressor gene p53 is the gene most frequently deleted or mutated in human tumors (Levine et al, 1991). These deletions or mutations may result in loss or alteration of the function of p53 protein (Zambetti and Levine, 1993). Mutations can lead to stabilization of the protein, resulting in higher levels of expression of mutant compared to normal p53 (Zambetti and Levine, 1993). The lower level expression of the unstable wild-type p53 (wtp53) can be induced following a toxic stimulus such as ionizing radiation; the induced level of p53 is also due to an increase in the half-life of the protein (Kastan et al, 1991). It is likely that p53 status directly affects therapeutic outcome, in that the cytotoxicity of some classes of chemotherapeutic agents is dependent on a functional nuclear p53 protein (Shaulsky et al, 1991; Lowe et al, 1993; Fan et al, 1994; Kohn et al, 1994). Therefore, it would be useful to have a simple reliable method with which normal or mutant p53 protein could be evaluated in small samples from primary tumors. Our first goal was to determine which p53 antibodies would be useful for detection and quantitation of $\mathrm{p} 53$ protein in tumor cell lines which express either wild-type or mutant p53. We were also interested in evaluating antibodies for their ability to determine the subcellular distribution of p53 within cells and to recognize wtp53 following induction with ionizing radiation.

Many antibodies are available that recognize epitopes on both mutant and wild-type p53 protein, but few data are available to document the antibody of choice to produce the most sensitive or the most specific p53 reactivity (Thomas et al, 1997; Bonsing et al, 1997). There is also little information available on the ability of each antibody to reliably reflect the subcellular distribution of p53, both before and after induction of protein expression following stimuli such as irradiation or drug treatment.

The study described here compared the immunoreactivity of p53 with five commercially available purified monoclonal antibodies both in immunoblot analysis of nuclear and cytoplasmic tumor cell fractions and in situ by immunofluorescence. The antibodies used were 1801 , DO1, DO7, BP53.12 and 421; the amino acids recognized by each antibody, as specified by the manufacturers, are listed in Table 1. These antibodies were chosen because they recognize both wild-type and mutant p53 protein, a characteristic which is essential when the p53 status of the tissue or cells to be evaluated is unknown.

\section{Results}

Specificity of antibodies on immunoblots

SDS-polyacrylamide gel electrophoresis of cell extracts prior to immunoblotting leads to denaturation of the native 
conformation of proteins such that antibody epitopes are not masked. Consequently, unless a particular antibody was raised against a conformation-specific epitope, all p53 protein within a cell should be visualized using any p53 antibody on immunoblots. By fractionating preparations of cells prior to electrophoresis and then doing immunoblot analysis, we were able to determine the subcellular distribution of p53 protein within the tumor cell lines. Figure $1 \mathrm{~A}$ shows the reactivity and specificity of antibodies 1801, DO1, DO7, BP53.12, and 421 on an immunoblot of nuclear- and cytoplasmic-enriched preparations of Rh28 (wtp53) cells. Fifteen $\mu \mathrm{g}$ of protein was loaded in each lane. Efficiency of fractionation was documented as detailed in Materials and Methods. Primary

\section{$1 \mathrm{~A}$}

\section{Rh28}

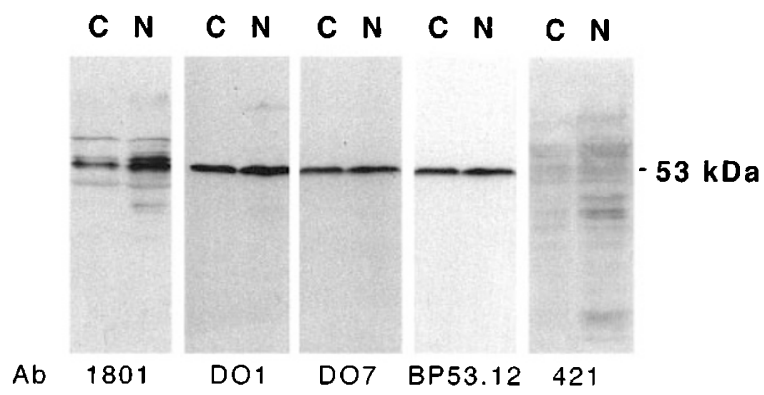

$1 B$

\section{Daoy}
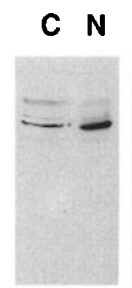

C $N$
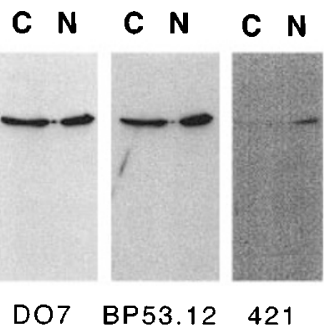

$53 \mathrm{kDa}$

Ab $\quad 1801$

D01

BP53.12 421

Figure 1 Immunoblot of p53 antibodies 1801, D01, D07, BP53.12, and 421 with cytoplasmic and nuclear-enriched protein preparations from Rh28 (wtp53) cells (A) and Daoy (mp53) cells (B). Cell Extracts were prepared and separated by electrophoresis as described in Materials and Methods. Specific antibody-antigen reactions were visualized by ECL detection methods, also as described in Materials and Methods antibodies were used at concentrations that optimized the signal to noise ratio, as listed in Table 1. Four of the five antibodies produced a prominent band at $53 \mathrm{kDa}$ in both the cytoplasmic and nuclear fractions of Rh28 (wtp53) cells, demonstrating high levels of expression of p53 protein in both cellular compartments. Antibody 421 gave no specific signal on immunoblots even after prolonged exposure of the blots to film. Approximately equal amounts of nuclear and cytoplasmic p53 were seen with antibodies DO1, DO7 and BP53.12. In contrast, results with 1801 showed threefold more p53/ $15 \mu \mathrm{g}$ protein in the nuclear compared to the cytoplasmic fraction of Rh28 cells. Figure 1B shows similar results with Daoy cells (mp53), with the single difference of a weak reaction with 421.

In both cell lines, 1801 also recognized additional bands of $\sim 57 \mathrm{kDa}$ and $\sim 75 \mathrm{kDa}$. The $57 \mathrm{kDa}$ band represented $35 \%$ and $15 \%$ of the signal in the nuclear and cytoplasmic preparations from Rh28 cells (wtp53), respectively, and $\sim 5 \%$ of the signal in both the cytoplasmic and nuclear preparations of the Daoy cells (mp53). The identity of these bands is unknown, but similar bands have been reported with 1801 in one other study (Banks et al, 1986) and a $57 \mathrm{kDa}$ band has also been reported with DO7 in a study by David-Pfeuty et al (1996). We conclude that 1801, DO1, DO7 and BP53.12 bind specifically to both wild-type and mutant p53 on immunoblots, and that 1801 cross-reacts with at least one other unidentified protein. In addition, these results demonstrate that both Rh28 (wtp53) and Daoy (mp53) cells express a high proportion of their p53 protein in the cytoplasm as well as in the nucleus. DO1, DO7 and BP53.12 produced a single, strong $53 \mathrm{kDa}$ band for both wtp53 and mp53.

\section{Specificity and sensitivity of antibodies in immunofluorescence assays}

In analyzing tumor samples, an insufficient amount of sample may be available with which to do immunoblot analysis, but frequently cells can be obtained for immunohistochemistry. Therefore, we performed indirect immunofluorescence assays with each antibody and compared immunofluorescence with immunoblot results in order to determine which antibody would be most suitable for analysis of p53 protein expression in situ. Figure $2 \mathrm{~A}$ shows photomicrographs of indirect immunofluorescence of Rh28 cells (wtp53) fixed with $1 \%$ paraformaldehyde and stained with antibodies 1801 , D01, DO7, BP53.12 or 421. The left hand panels show the

Table 1 Monoclonal antibodies reported to recognize both wild type and mutant p53 protein

\begin{tabular}{|c|c|c|c|c|}
\hline \multirow[b]{2}{*}{ Antibody (Source) ${ }^{a}$} & \multirow[b]{2}{*}{ Epitope $^{\text {b }}$} & \multirow[b]{2}{*}{ Isotype } & \multicolumn{2}{|c|}{ Concentration of antibody } \\
\hline & & & Immunofluorescence & Immunoblot \\
\hline 1801 (ORP) & $46-55$ & $\lg G_{1}$ & $3 \mu \mathrm{g} / \mathrm{ml}$ & $1 \mu \mathrm{g} / \mathrm{ml}$ \\
\hline DO1 (SCB) & $11-25$ & $\lg _{2 a}$ & $0.1 \mu \mathrm{g} / \mathrm{ml}$ & \\
\hline DO1-HRP (SCB) & $11-25$ & $\lg _{2 a}$ & & $0.5 \mu \mathrm{g} / \mathrm{ml}$ \\
\hline DO7 (P) & $1-45$ & $\lg _{2 b}$ & $1 \mu \mathrm{g} / \mathrm{ml}$ & $0.2 \mu \mathrm{g} / \mathrm{ml}$ \\
\hline BP53.12 (ORP) & $18-30$ & $\lg _{2 a}$ & $3 \mu \mathrm{g} / \mathrm{ml}$ & $0.5 \mu \mathrm{g} / \mathrm{ml}$ \\
\hline 421 (ORP) & $371-380$ & $\lg _{2 a}$ & $3 \mu \mathrm{g} / \mathrm{ml}$ & $10 \mu \mathrm{g} / \mathrm{ml}$ \\
\hline
\end{tabular}

${ }^{a}$ ORP, Oncogene Research Products, Cambridge, MA. SCB, Santa Cruz Biotechnology, Inc., Santa Cruz, CA. P, Pharmingen, San Diego, CA. bamino acid residues 
isotype matched negative controls for each antibody. The middle panels show indirect immunofluorescence for p53 with each of the five antibodies included in the study; and the right hand panels show the Hoechst stains (DNA) of the same field of cells as is pictured in the middle panels, to define the nucleus of the cells in each field. Figure 2B shows similar photomicrographs of Daoy (mp53) cells.

Levels of nuclear immunofluorescence seen in images in Figure $2 \mathrm{~A}$ and $\mathrm{B}$ were quantitated by image cytometric techniques, and results of these quantitations are expressed as nuclear fluorescence units are shown in Figure 3. Under the conditions used, all five antibodies produced specific nuclear fluorescence in both cell lines. As would be expected, the mutant p53 cell line (Daoy) expressed a higher level of p53 than the wild-type p53 cell line (Rh28), as detected by all five antibodies. In both cell lines, 1801 produced the highest levels of fluorescence.

In addition to the observed nuclear fluorescence, 1801, BP53.12 and 421 also produced cytoplasmic fluorescence in both cell lines. Notably, the pattern of cytoplasmic staining with 1801 differed from that obtained with BP53.12

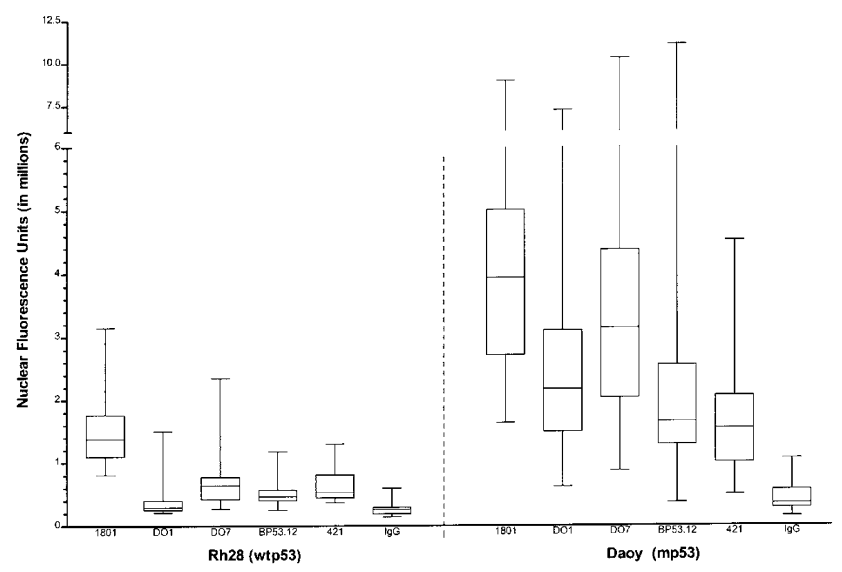

Figure 3 Quantitation of nuclear fluorescence of Rh28 (A) cells and Daoy (B) cells with each of the indicated p53 antibodies. Fluorescence is expressed as nuclear fluorescence units. Bar and whisker analyses were done with GraphPad Prism software. The boxed area represents fluorescence of $50 \%$ of cells included in each analysis, $25 \%$ above the median (line in the middle of the box) and $25 \%$ below the median. Bars represent the range of values obtained. Fluorescence of approximately 50 cells was quantitated for each analysis
A

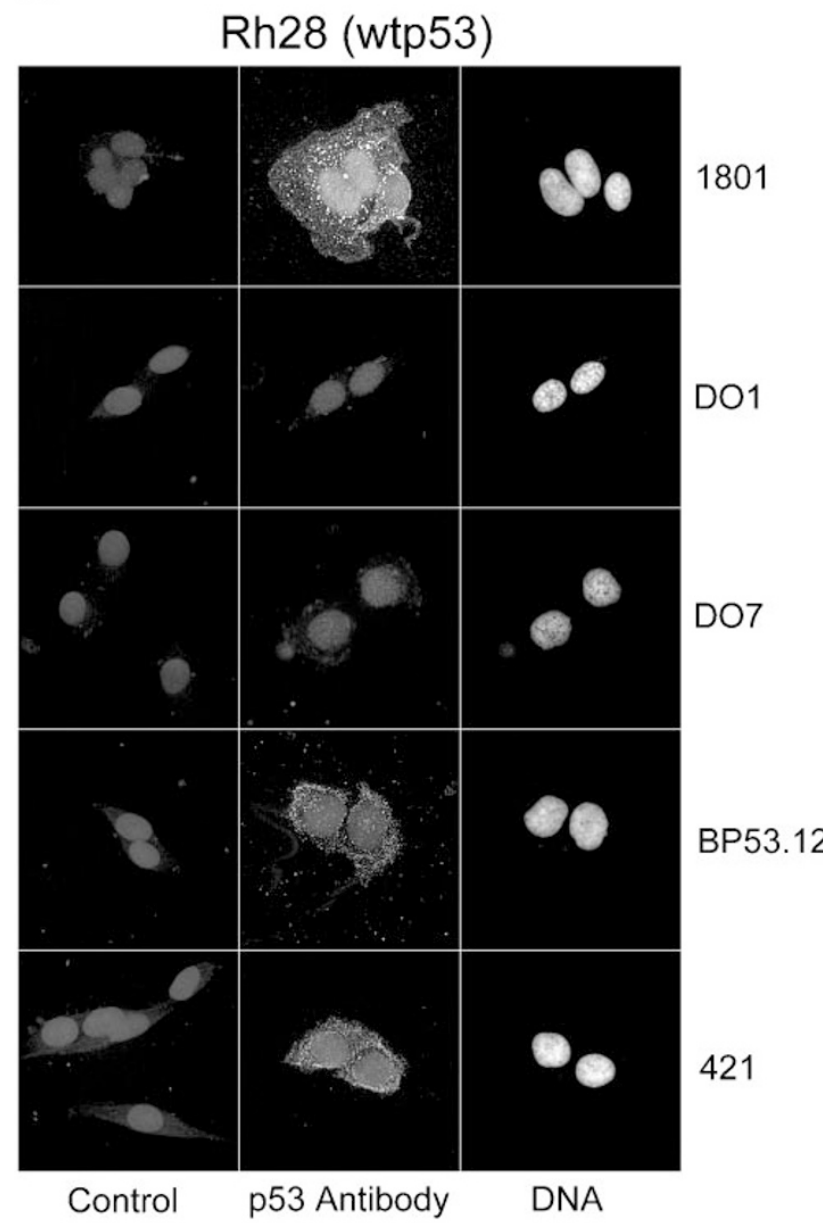

B

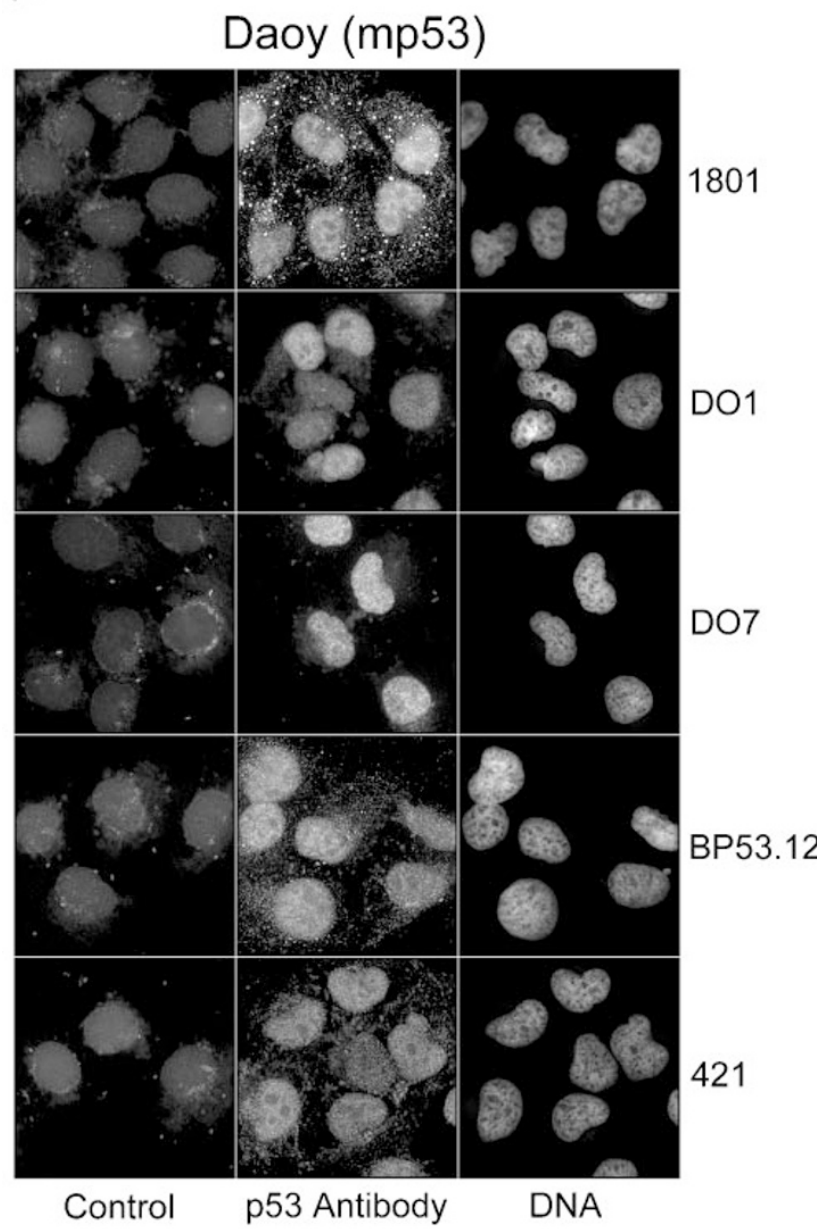

Figure 2 (A) Indirect immunofluorescence staining of Rh28 cells (wtp53) with five p53 antibodies. (B) Equivalent staining of Daoy (mp53) cells. Procedural details are found in Materials and Methods 
and 421 in that with 1801 the cytoplasmic staining pattern appeared more globular than stippled as was seen with BP53.12 and 421. All of the above stains were also performed with NB-1643 neuroblastoma cells which express wtp53 and showed similar results (Figure 7, to be described later).

The comparatively high level of fluorescence seen with 1801 suggested that either the epitopes recognized by this antibody were more accessible for antibody binding than the epitopes recognized by BP53.12 and 421, or that, similar to results with immunoblots, 1801 cross-reacted in situ with other protein(s) in addition to p53. The ability of 421 to recognize p53 in situ (Figure 2) but not on immunoblots (Figure 1), suggests that epitope recognition by this antibody is at least partially dependent upon the three-dimensional structure of the protein.

To determine whether the nuclear and cytoplasmic fluorescence apparent with each antibody were, in fact specific to p53, we repeated the above experiment with Saos2 cells which express no p53 mRNA or protein (Takahashi et al, 1989; Mitsudomi et al, 1992). Figure 4 shows immunofluorescence images arranged in a similar

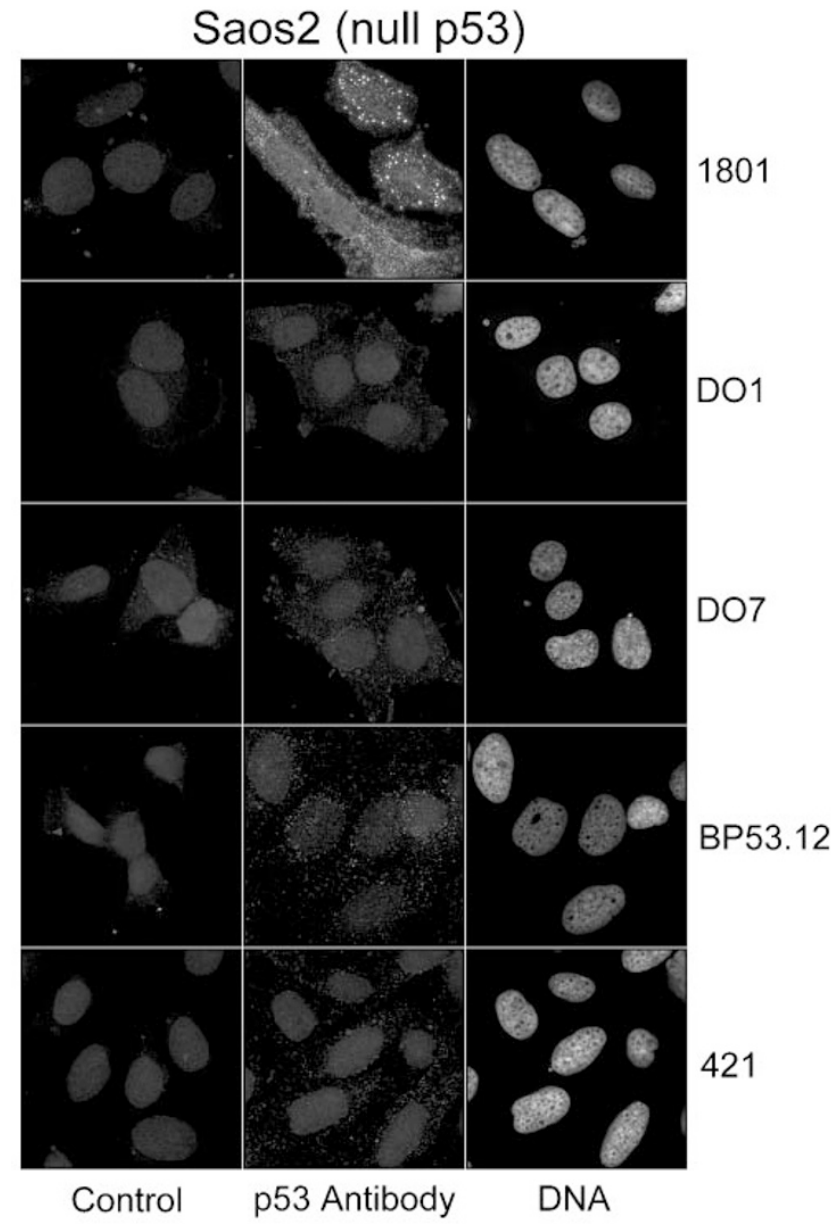

Figure 4 Indirect immunofluorescence staining of Saos2 cells (null for p53) with five p53 antibodies. Methods are as detailed in Materials and Methods fashion as Figure 2. The left panels contain negative control data; the middle panels show the results obtained with each of the five antibodies; and the right panels show positions of the nuclei. Antibodies DO1, DO7, BP53.12 and 421 did not stain these p53-negative cells as would be expected; however, nuclear as well as cytoplasmic fluorescence was deteted with 1801. Quantitation of the level of nuclear fluorescence of Saos2 cells with all five antibodies is shown in Figure 5. These data again suggest that 1801 is binding to a protein(s) other than p53. Results with a second p53 null cell line, H358 (Goldsmith et al, 1995), stained with DO1, DO7 and 1801 were similar to those shown in Figure 4 (data not shown).

For all cell lines and antibodies, cells fixed with methanol/acetone gave results comparable to those obtained with cells fixed with paraformaldehyde (data not shown); results obtained are, therefore, unlikely to be artifacts of the fixation procedure. To confirm that the Saos2 and H358 cells were indeed negative for p53 protein expression, whole cell extracts were analyzed by immunoblot using the DO1 antibody. No signal was detected after a $10 \mathrm{~min}$ exposure to X-ray film (data not shown); whereas,

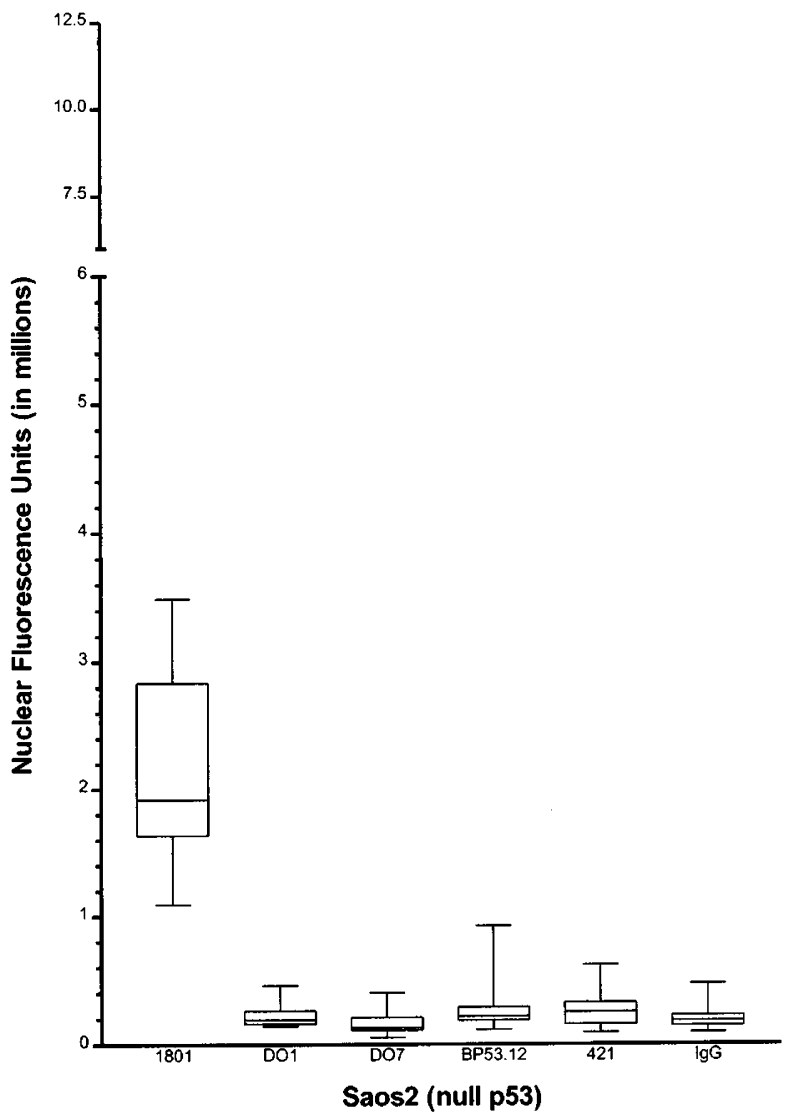

Figure 5 Quantitation of nuclear fluorescence of Saos2 cells with each of the indicated p53 antibodies. Fluorescence is expressed as nuclear fluorescence units. Bar and whisker analyses were done with GraphPad Prism software. The boxed area represents fluorescence of $50 \%$ of cells included in each analysis, $25 \%$ above the median (line in the middle of the box) and $25 \%$ below the median. Bars represent the range of values obtained 
only $5 \mathrm{~s}$ were required to detect the specific signal in Daoy cells (Figure 1B).

Because the data in Figures 1, 4 and 5 suggested that 1801 might, indeed, be recognizing a protein other than p53, we reprobed the immunoblots of Saos2 cells with 1801 and exposed the blots to X-ray film for $20 \mathrm{~min}$. As might be expected, this prolonged exposure of the blots showed numerous diffuse bands ranging in size from $30-$ $100 \mathrm{kDa}$ (data not shown). However, it is not known whether these bands result from recognition of a specific epitope by the 1801 antibody or whether they represent nonspecific background staining. We conclude that 1801 is unreliable in immunofluorescence assays and, consistent with immunoblot analysis (Figure 1), likely reacts with another protein(s) in addition to p53. However, no amino acid sequence homologous to the epitope of 1801 other than the human p53 protein itself could be identified in the Swiss-Prot Protein sequence database (Bairuch and Apweiler, 1997). This data base contains the sequence of the recently identified p53-family member p73 (Kaghad et al, 1997).

Figure 2 shows that DO1 and DO7 generate only nuclear staining. Therefore, although these antibodies can be used for specific detection of nuclear p53 protein, they are not the antibodies of choice for determination of subcellular distribution of p53. The antibodies of choice for immunofluorescence analysis of the subcellular localization of p53 are 421 and BP53.12 because, as demonstrated in Figure 2, these antibodies recognize cytoplasmic as well as nuclear p53 protein.

In conclusion, the above data indicate that on immunoblots, 1801, DO1, DO7, and BP53.12 reliably detect both nuclear and cytoplasmic, wild-type and mutant p53. In situ, DO7 appears to be the most sensitive and specific in detecting nuclear p53, but this antibody does not recgonize the cytoplasmic protein. Antibodies BP53.12 and 421 detect both nuclear and cytoplasmic p53 in situ; but the nuclear fluorescence intensity seen with these two antibodies is less than that seen with the others tested. The highest level of fluorescence intensity in situ was obtained using 1801; but this antibody does not appear to be specific for p53 protein.

\section{Detection of wtp53 following induction by ionizing radiation}

In cells containing functional wild-type p53, the amount of cellular p53 increases following DNA damage (Fritsche et al, 1993). If this induction could be detected by immunofluorescence, it might be possible to assess the functional status of p53 and the subcellular localization of the induced protein in small samples. NB-1643 (wtp53) cells were chosen for these experiments after it was confirmed that they could induce expression of functional wtp53 protein following DNA damage (Figure 6). The immumoblot analysis in this figure demonstrates enhanced expression of both p53 itself and also of the cyclin-dependent kinase inhibitor p21 (El-Deiry et al, 1994) $4 \mathrm{~h}$ following exposure to $1.25 \mathrm{~Gy}$ ionizing radiation. This dose represents the $\mathrm{IC}_{80}$ in that it inhibits growth of irradiated cultures by $80 \%$ compared to untreated cells. The data shown

\section{NB-1643 (wtp53)}

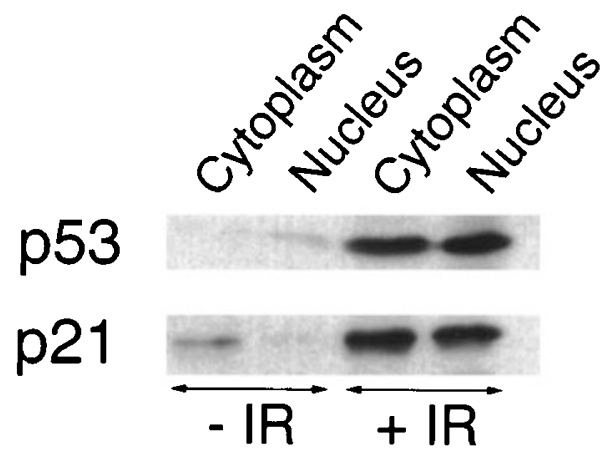

Figure 6 Immunoblot analysis of protein preparations of NB-1643 neuroblastoma cells (wtp53) with the D01 antibody to p53 and the Sdi1 antibody to $\mathrm{p} 21$. Cell Extracts were prepared and separated by electrophoresis as described in Material and Methods. Specific antibody-antigen reactions were visualized by ECL detection methods, also as described in Materials and Methods

in Figure 6 also demonstrates that both nuclear and cytoplasmic p53 can be induced approximately fourfold.

NB-1643 neuroblastoma cells treated in a similar manner, but assessed by immunofluorescence assay with all five antibodies, are shown in Figure 7. Only DO7 and BP53.12 detected the increase in nuclear p53, and only BP53.12 detected the increase in both nuclear and cytoplasmic p53. Similar results were obtained when cells were fixed with either paraformaldehyde or with acetone/ methanol. In summary, while all five antibodies recognize nuclear p53, only two of the five show the increase in nuclear p53 following irradiation. The data suggest that, in addition to the above-noted conformational differences between nuclear and cytoplasmic p53, nuclear p53 exists in at least two different conformations or states of protein binding following lethal doses of irradiation. Both forms can be recognized by DO7 and BP53.12 whereas only the uninduced form can be recognized by 1801, DO1 and 421 . These results were unexpected since, for example, the epitopes for DO1 and DO7 are similar (both within the first 45 amino acids of the amino terminus of the p53 protein) (Table 1), but DO7 recognized induced p53 while DO1 did not.

\section{Discussion}

Many studies have been done that rely on the sensitivity and specificity of p53 antibodies to evaluate p53 status of primary tumor samples (for example, Ayan et al, 1997; Cattaoretti et al, 1988; Deng et al, 1994; Domagala et al, 1993; Esposito et al, 1997; Varley et al, 1991; Yoo et al, 1997). In addition, antibody 1801 has been used to show association of p53 with centrosomes (Brown et al, 1994), cytoplasmic distribution of p53 in neuroblastoma cells (Moll et al, 1996), and to quantitate p53 in tumor cells (Sjogren et al, 1996; Bhattacharjee and Bruner, 1997). Data presented here show that the ability to interpret studies such as these is very dependent on the 
antibody used and whether conditions can be identified that optimize the signal to noise ratio for each type of assay.

The novel findings presented here are several: (1) Contrasts in epitope accessibility of p53 suggest that

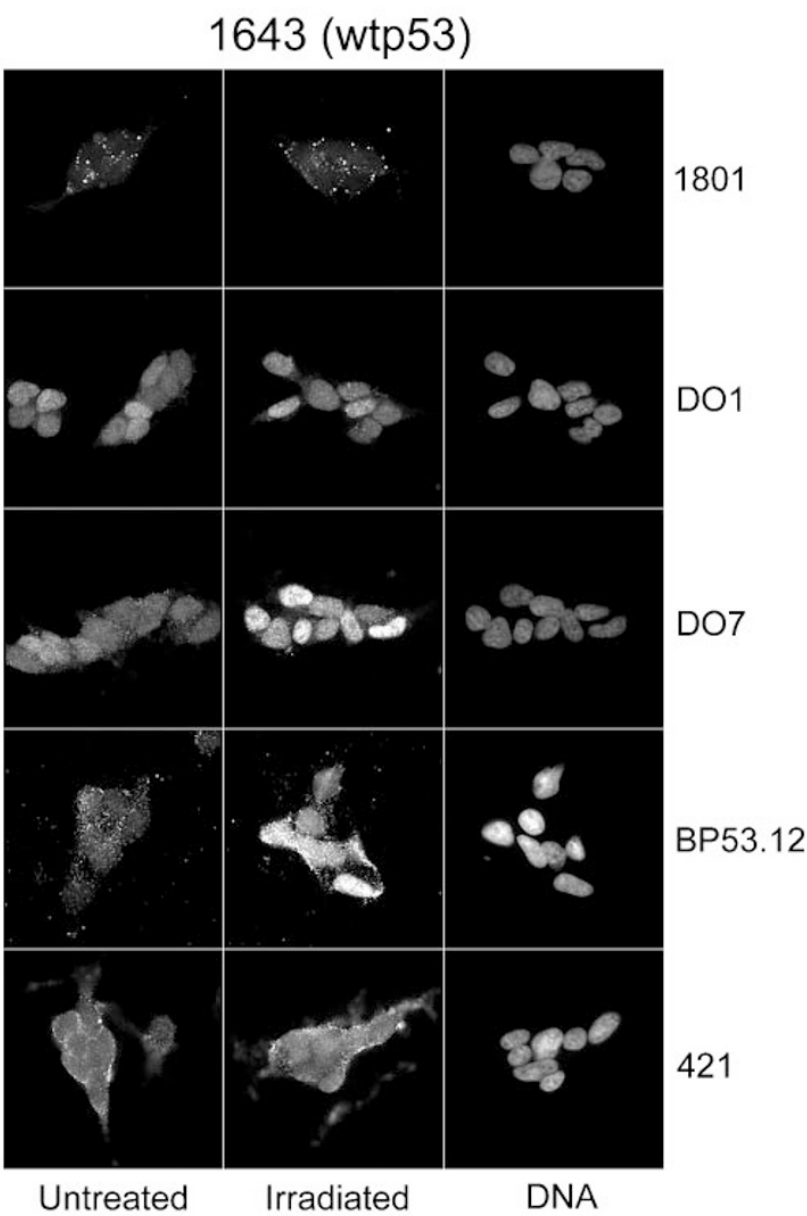

Figure 7 Indirect immunofluorescence staining of NB-1643 cells (wtp53) with five p53 antibodies. Procedural details are found in Materials and Methods. Left-hand panels show untreated control cells. Center panels show cells $4 \mathrm{~h}$ following exposure to an $\mathrm{IC}_{80}$ dose of ionizing radiation which is known to induce expression of p53 as demonstrated in Figure 6. Both Left and Center panels show results of indirect immunofluorescence with the indicated p53 antibody. Right-hand panels show the DNA stain (Hoechst 33342) to define the area of the nucleus of the cells shown in the middle panels. Antibody 1801 is printed at an tenfold lower intensity than the other antibodies to allow comparison of fluorescence intensity prior to and following ionizing radiation nuclear and cytoplasmic p53 have distinct three-dimensional conformations or states of protein binding; (2) Similarly, contrasts in epitope accessibility of induced and uninduced nuclear p53 indicate that a third protein conformation exists following exposure of cells to ionizing irradiation; (3) DO7 and BP53.12 appear to be the most sensitive and specific in situ in detecting nuclear p53 both before and after irradiation; and (4) BP53.12 is the antibody most specific and reliable for describing the subcellular localization of p53 in irradiated and unirradiated cells.

Results shown in Figure 1 demonstrated that 421 was not a good antibody for immunoblot analysis. Both Bonsing et al (1997) and Banks et al (1986) have also documented that 421 has poor reactivity on immunoblots; however, Banks et al also showed that 421 has better reactivity against murine p53 than human p53.

Bonsing et al performed quite an extensive study comparing seven antibodies in several types of assays. However, immunoblots published by those authors demonstrated that all of the antibodies tested recognized numerous proteins bands, although most of these bands were described as non-specific. In addition, these authors did not address the significance of cytoplasmic immuno-staining or antibody reactivity with induced p53. In agreement with the Bonsing study, however, we show that 1801 did appear to recognize p53 as well as additional proteins on immunoblots. We also describe assay conditions under which three p53 antibodies (DO1, DO7 and BP53.12) produce clear, single and strong $53 \mathrm{kDa}$ bands. Differences in results between the two studies may derive from the fact that our assay conditions were optimized for each antibody, whereas the data shown by Bonsing et al were generated by using a single immunoglobulin concentration for all antibodies. The conditions for use on immunoblots and reactivity for each of the five antibodies in our study are listed in Tables 1 and 2 and shown in Figure 1.

Several previous reports (Bodner et al, 1992; Cattoretti et al, 1998; Deng et al, 1994; Moll et al, 1996; Varley et al, 1991) also indicate that 1801 reacts with cytoplasmic antigens. However, these studies did not investigate whether the cytoplasmic reactivity specifically represented p53 or another protein unrelated to p53. We have shown that using 1801 a high level of p53 is found in the cytoplasm both of cells that express wild-type and mutant p53. However, Saos2 cells which are null for p53 demonstrate cytoplasmic immunofluorescence staining in situ with 1801 and consequently we conclude (as did the Bonsing study) that this antibody reacts with at least one

Table 2 Reactivity in situ of five p53 antibodies in Rh28 and NB-1643 (wild type p53), Daoy (mutant p53), or Saos2 (negative p53) cells fixed with 1\% paraformaldehyde or acetone: methanol

\begin{tabular}{|c|c|c|c|c|c|c|c|c|}
\hline \multirow{2}{*}{$\frac{\text { Antibody }}{1801}$} & \multicolumn{2}{|c|}{$\begin{array}{c}\text { Rh28 (wtp53) } \\
\text { Nucleus Cytoplasm }\end{array}$} & \multicolumn{2}{|c|}{$\begin{array}{c}\text { Daoy (mutant 53) } \\
\text { Nucleus Cytoplasm }\end{array}$} & \multicolumn{2}{|c|}{$\begin{array}{c}\text { Saos2 (negative p53) } \\
\text { Nucleus Cytoplasm }\end{array}$} & \multicolumn{2}{|c|}{$\begin{array}{c}\text { NB-1643 (induced p53) } \\
\text { Nucleus Cytoplasm }\end{array}$} \\
\hline & + & + & + & + & + & + & - & - \\
\hline DO1 & + & - & + & - & - & - & - & - \\
\hline DO7 & + & - & + & - & - & - & + & - \\
\hline BP53.12 & + & + & + & + & - & - & + & + \\
\hline 421 & + & + & + & + & - & - & - & - \\
\hline
\end{tabular}


other protein and is not considered to be the antibody of choice for in situ evaluation (or immunoblot analysis) of p53.

Immunoblot analysis as shown in Figure 1 demonstrated that there was a high proportion of p53 expressed in the cytoplasm as well as in the nucleus. Therefore, it was interesting that two antibodies, DO1 and DO7, were unable to recognize cytoplasmically localized p53 in situ. In contrast, antibodies BP53.12 and 421 specifically recognized cytoplasmic p53 in situ. These results suggest that there are different conformations or state of protein binding of p53 protein within cells which mask the epitopes of certain p53 antibodies. Since p53 induction occurs posttranscriptionally (Kastan et al, 1991), it is likely that the protein undergoes conformational changes, oligomerizes (Kraiss et al, 1988), or binds to other proteins, thereby mediating its stabilization and masking antibody epitopes. Different conformations of p53 protein have previously been identified during keratinocyte differentiation (Spandau, 1994) and p53 has been reported to bind to many different proteins including topoisomerase I (Gobert et al, 1996), p34 ${ }^{\mathrm{cdc} 2}$ (Sturzbecher et al, 1990), MDM2 (Momand et al, 1992), heat shock proteins (Pinhasi-Kimhi et al, 1986), SV40 T antigen (Jenkins et al, 1988), human papillomavirus types 16 and $18 \mathrm{E} 6$ proteins (Werness et al, 1990), and the TATA-binding protein (Seto et al, 1992).

Additionally, Spandau described various in situ staining patterns throughout layers of the epidermis when using a panel of p53 antibodies, and proposed that p53 may be involved in several different processes, requiring different protein conformations during the development and terminal differentiation of a keratinocyte. Milner and Watson (1990) reported that wtp53 immunoreactivity with Ab246 changes following growth stimulation, reflecting conformational and functional differences in wtp53 protein.

In summary, except for the fact that DO7 does not recognize cytoplasmic p53 in situ, we found it to be the most specific, versatile and reliable antibody. We also conclude that the antibody used for a particular study must be chosen with the specific goal of the study in mind, since results with each of the five antibodies vary significantly, and the data can be interpreted only if results with isotypematched negative controls and p53 null cells are available.

\section{Materials and Methods}

\section{Cell lines and tissue culture}

The cell lines with wild-type p53 that were used in this study were Rh28 rhabdomyosarcoma cells and NB-1643 neruoblastoma cells. The Rh28 cell line was established by Hazelton et al (1987) from the rhabdomyosarcoma of a pediatric patient at St. Jude Children's Research Hospital. The NB-1643 cell line is of neuroblastoma origin and was obtained from the Pediatric Oncology Group cell bank. Rh28 and NB-1643 cells were cultured in RPMI-1640 (Biowhitaker, Walkersville, MD) supplemented with $10 \%$ fetal calf serum (Hyclone, Logan, UT) and incubated at $37^{\circ} \mathrm{C}$ in a humidified atmosphere of $5 \%$ $\mathrm{CO}_{2}, 95 \%$ air. These cell lines were determined to be wild-type for the p53 gene by sequencing of genomic DNA (Houghton and Harris, unpublished observations). The cell line expressing mutant p53 used for the study was the Daoy cell line from the medulloblastoma of a pediatric patient, Daoy cells express mutant p53, having a $T$ substituted for a $G$ in position 2 of codon 242, which results in an amino acid change from cysteine to phenylalanine (Saylors et al, 1991). Daoy cells were cultured in DMEM (Biowhitaker) supplemented with $15 \%$ fetal calf serum in a humidified atmosphere of $10 \% \mathrm{CO}_{2}$, $90 \%$ air. The cell lines that do not express p53 that were used in the study were the Saos2 osteogenic sarcoma and H358 lung carcinoma cell lines (obtained from Dr G.P. Zambetti, St Jude Children's Research Hospital). These cell lines were cultured in DMEM supplemented with $10 \%$ fetal calf serum.

\section{Antibodies}

Characteristics, assay conditions, and sources for obtaining all five antibodies included in the study are listed in Table 1. For immunoblots, antibodies were diluted in BLOTTO $(5 \%$ nonfat dried milk in TBS-T: $20 \mathrm{mM}$ Tris- $\mathrm{HCl}(\mathrm{pH} 7.4), 137 \mathrm{mM} \mathrm{NaCl}$ and $0.1 \%$ Tween 20); for immunofluorescence assays, antibodies were diluted in 1\% BSA/PBS. The Sdi1 antibody to p21 was obtained from Pharmingen (San Diego, CA). FITC-conjugated donkey anti-mouse IgG was obtained from Jackson ImmunoResearch Laboratories, Inc. (West Grove, PA) and was used at a final concentration of $2.5 \mu \mathrm{g} / \mathrm{ml}$ in $1 \%$ BSA in PBS.

\section{Cell fractionation}

Cells were fractionated into nucleus-enriched and cytoplasm-enriched fractions as previously published (Danks et al, 1996). Briefly, cells were scraped into cold isotonic homogenization buffer $(10 \mathrm{mM}$ Tris$\mathrm{HCl}(\mathrm{pH} \mathrm{7.4)}, 140 \mathrm{mM} \mathrm{KCl}, 1.5 \mathrm{mM} \mathrm{MgCl} 2$ ) containing freshly prepared protease inhibitors. Cytoplasmic membranes were disrupted by 25-50 strokes of a glass homogenizer and permeabilization of the membranes was confirmed by trypan blue staining of $>90 \%$ of the cells. The homogenized preparation was centrifuged at $1000 \times g$ for $10 \mathrm{~min}$ at $4{ }^{\circ} \mathrm{C}$, to separate the nucleus-enriched fraction (pellet) from the cytoplasm-enriched supernatant. The nuclear pellet was resuspended in additional homogenization buffer and sonicated to disrupt the DNA. The efficiency of fractionation was determined by quantitating the DNA in each fraction and also by immunoblots with anitbodies specific to nuclear or cytoplasmic proteins. By this method, DNA was quantitated using Hoechst 33258 and a Hoefer TKO 100 fluorometer (San Francisco, CA) according to the manufacturer's instructions. DNA was routinely detected only in the nuclear fractions, indicating no detectable contamination of the cytoplasmic fraction with nuclear material; and immunoblot analysis with MEK-2, a cytoplasmic marker protein (Zheng and Guan, 1994), showed a $7 \%$ contamination of the nuclear fraction with cytoplasmic protein, a level considered acceptable to allow interpretation of data obtained for p53 immunoblots.

\section{Immunoblot analysis}

Preparations of nuclear and cytoplasmic proteins were electrophoresed in 12.5\% SDS-polyacrylamide gels, using the BioRad Mini Protean II system. Proteins were electroblotted to polyvinylidine fluoride membranes (Immobilon-P; Millipore, Bedford, MA) using the BioRad Mini electroblotter. Membranes were blocked in BLOTTO for $1 \mathrm{~h}$ at room temperature, followed by incubation for another hour with 1801, DO7, BP53.12 or 421 or a DO1 antibody conjugated to horseradish peroxidase (Santa Cruz Biotechnology Inc., Santa Cruz, CA) diluted in BLOTTO to the concentrations indicated in Table 1. 
After three washes in TBS-T, the membrane was incubated with secondary antibody, (HRP-conjugated donkey anti-mouse IgG from Amersham, Arlington Heights, IL) when appropriate for an hour. The final three washes with TBS-T consisted of two washes for $15 \mathrm{~min}$ and one wash for $30 \mathrm{~min}$ following which Enhanced ChemiLuminescence (ECL; Amersham) detection reagents were used as described by the manufacturer. The length of exposure for development of blots with 1801, DO1, DO7 and BP53.12 varied from a few seconds to $10 \mathrm{~min}$ to generate appropriate band intensity. Blots with 421 were exposed to $\mathrm{X}$-ray film for $45 \mathrm{~min}$. Proteins were visualized by exposure to $\mathrm{X}$-ray film (Kodak X-Omat AR; Eastman Kodak Co., Rochester, NY). These films were scanned using a UMAX PowerLookll scanner and bands were quantitated using Microsoft ImageQuant software.

\section{Indirect immunofluorescence staining}

Stains were done as described previously (Danks et al, 1996, 1997) with minor modifications. Cells were grown on glass chamber well slides (Nunc, Naperville, IL) and fixed with either freshly prepared $1 \%$ paraformaldehyde at room temperature for $20 \mathrm{~min}$ or acetonemethanol $(1: 1)$ at $-20^{\circ} \mathrm{C}$ for $2 \mathrm{~min}$. All subsequent procedures were carried out at room temperature. When cells were fixed with paraformaldehyde, nuclear membranes were permeabilized with $0.25 \%$ Triton X-100 in PBS for 20 min. Cells were then washed three times with PBS and incubated with 10\% swine serum for $20 \mathrm{~min}$ to minimize nonspecific binding of antibodies. Incubation with the appropriate concentration of primary antibody (Table 1) or an isotype matched control (the normal mouse immunoglobulin fraction diluted to the same protein concentration) was for $2 \mathrm{~h}$ in a humidified chamber. Cells were washed with PBS for $10 \mathrm{~min}$, changing the wash solution five times during this period. The cells were then incubated with a FITC-conjugated donkey anti-mouse IgG for $1 \mathrm{~h}$. After washing in PBS for $10 \mathrm{~min}$, cells were incubated with Hoechst 33342 for 2 min to visualize the DNA. Slides were air-dried before mounting.

\section{Fluorescence image cytometry}

To eliminate investigator bias, fields of cells to be analyzed for p53 were chosen on the basis of Hoechst (DNA) fluorescence. DNA fluorescence was used to confirm that nuclei were intact, nonoverlapping, and in a single focal plane. DNA images of cells meeting these criteria were acquired and stored for analysis. All FITC images were exposed for $5 \mathrm{~s}$. An occasional field of cells was not recorded for analysis if the cytoplasmic fluorescence was not in a single focal plane.

The method for quantitation of nuclear fluorescence was basically as described previously (Danks et al, 1996, 1997). The procedure to quantitate nuclear fluorescence was modified slightly to exclude the intense punctate cytoplasmic staining when present over the nucleus. With the exception of Figure 7, all images in any given figure are printed at the same contrast to allow direct comparison of fluorescence intensities among antibodies. In Figure 7, 1801 staining is shown ten times less intense than the other antibodies in order to allow comparison of staining prior to and following radiation.

\section{Acknowledgements}

This work was supported by NIH Grants CA-63512, CA-23099, the Cancer Centre Core Grant P30-CA-21765 and the American Lebanese Syrian Associated Charities.

\section{References}

Ayan I, Dogan O, Kebudi R, BavbekB, Alatli C, Dervisoglu S, Disci Rand DemiryontM (1997) Immunohistochemical detection of p53 protein in rhabdomyosarcoma: Association with clinicopathological features and outcome. J. Ped. Hematol/ Oncol. 19: 48-53

Bairoch A and Apweiler R (1997) The SWISS-PROT protein sequence data bank and its supplement TrEMBL. Nucleic Acids Res. 25: 31-36

Banks L, Matlashiewski G and Crawform L (1986) Isolation of human-p53-specific monoclonal antibodies and their use in the studies of human p 53 expression. Eur. J. Biochem. 159: 529-534

Bhattacharjee MB and Bruner JM (1997) p53 Protein in pediatric malignant astrocytomas: A Study of 21 patients. J. Neuro-Oncol. 32: 225-233

Bodner SM, Minna JD, Jensen SM, D'Amico D, Carbone D, Mitsudomi T, Fedorko J, Buchhagen DL, Nau MM, Gazdar AF and Linnoila RI (1992) Expression of mutant p53 proteins in lung cancer correlates with the class of p53 gene mutation. Oncogene 7: 743-749

Bonsing BA, Corver WE, Gorsira MCB, vanVliet M, Oud PS, Cornelisse CJ and Fleuren GJ (1997) Specificity of seven monoclonal antibodies against p53 evaluated with Western blotting, immunohistochemistry, confocal laser scanning microscopy, and flow cytometry. Cytometry 28: $11-24$

Brown CR, Doxsey SJ, White E and Welch WJ (1994) Both viral (adenovirus E1B) and cellular (hsp70, p53) components interact with centrosomes. J. Cell. Phys. 160: 47-60

Cattoretti G, Rilke F, Andreola S, D'Amato L and Delia D (1988) Expression in breast cancer. Int. J. Cancer 41: 178-183

Danks MK, Garrett KE, Marion RC and Whipple DO (1996) Subcellular redistribution of DNA topoisomerase I in anaplastic astrocytoma cells treated with topotecan. Cancer Res. 56: 1664 - 1673

Danks MK, Pawlik CA, Whipple DO and Wolverton JS (1997) Intermittent exposure of medulloblastoma cells to topotecan produces growth inhibition equivalent to continuous exposure. Clin. Cancer Res. 3: 1731-1738

David-Pfeuty T, Chakrani F, Ory K and Nouvian-Dooghe Y (1996) Cell cycledependent regulation of nuclear p53 traffic occurs in one subclass of human tumor cells and in untransformed cells. Cell Growth and Differentiation 7: $1211-$ 1225

Deng G, Chen LC, Schott DR, Thor A, Bhargava V, Ljung BM, Chew K and Smith HS (1994) Loss of heterozygosity and p53 gene mutations in breast cancer. Cancer Res. 54: 499-505

Domagala W, Harenzga B, Szadowska A, Mariewski M, Weber K and Osborn M (1993) Nuclear p53 protein accumulates preferentially in medullary and highgrade ductal but rarely in lobular breast carcinomas. Am. J. Pathol. 142: 669674

El-Deiry WS, Harper JW, O'Conner PM, Velculescu VE, Canman CE, Jackman J, Pietenpol JA, Burrell M, Hill DE, Wang Y, Wiman KG, Mercer WE, Kastan MB, Kohn KW, Elledge SJ, Kinzler KW and Vogelstein B (1994) WAF1/CIP1 is induced upon p53-mediated growth arrest and apoptosis. Cancer Res, 54: $1169-1174$

Esposito V, Balda A, DeLuca A, Claudio PP, Signoriello G, Bolognese A, Centonze P, Giordano GG, Caputi M, Baldi F and Giordano A (1997) p53 Immunostaining in differential diagnosis of pleural mesothelial proliferations. Anticancer Res. 17: $733-736$

Fan S, EIDiery WS, Bae I, Freeman J, Jondel D, Blatia K, Fornace AJ, Magrath I, Kohn KW and O'Connor PM (1994) p53 Gene mutations are associated with decreased sensitivity of human lymphoma cells to DNA damaging agents. Cancer Res. 54: 5824-5830

Fritsche M, Haessler C and Bradner G (1993) Induction of nuclear accumulation of the tumor-suppressor protein $p 53$ by DNA damage. Oncogene 8: 307-318

Gobert C, Bracco L, Rossi F, Olivier M, Tazi J, Lavelle F, Larsen AK and Riou JF (1996) Modulation of DNA topoisomerase I activity by p53. Biochemistry 35 : $5778-5786$

Goldsmith ME, Gudas JM, Schneider E and Cowan KH (1995) Wild-type p53 stimulates expression from the human multidrug resistance promoter in a $\mathrm{p} 53$ negative cell line. J. Biol. Chem. 270: 1894-1898

Hazelton BJ, Houghton JA, Parham DM, Douglass EC, Torrance PM, Holt $\mathrm{H}$ and Houghton PJ (1987) Characterization of cell lines derived from xenografts of childhood rhabdomyosarcoma. Cancer Res. 47: 4501-4507 
Jenkins JR, Chumakov P, Addison C, Sturzbecher HW and Wade-Evans A (1988) Two distinct regions of the murine p53 primary amino acid sequence are implicated in stable complex formation with simian virus $40 \mathrm{~T}$ antigen. J. Virol. 62 : 3902-3906

Kaghad M, Bonnet H, Yang A, Creancier L, Biscan JC, Valent A, Minty A, Chalon P, Lelias JM, Dumont X, Ferrara P, McKeon F and Caput D (1997) Monoallelically expressed gene related to $\mathrm{p} 53$ at $1 \mathrm{p} 36$, a region frequently deleted in neuroblastoma and other human cancers. Cell 90: 809-819

Kastan MB, Onyekwere O, Sidransky D, Vogelstein B and Craig RW (1991) Participation of $p 53$ protein in the cellular response to DNA damage. Cancer Res. 51: 6304-6311

Kohn KW, Jackman J and O'Connor PM (1994) Cell cycle control and cancer chemotherapy. J. Cell. Biochem. 54: 440-452

Kraiss S, Quaiser A, Oren M and Montenarh M (1988) Oligomerization of oncoprotein p53. J. Virol. 62: 4737-4744

Levine AJ, Momand J and Finlay CA (1991) The $p 53$ tumor suppressor gene. Nature 351: 453-455

Lowe SW, Ruley HE, Jacks T and Houseman E (1993) p53-Dependent apoptosis modulates the cytotoxicity of anticancer agents. Cell 74: 957-967

Milner J and Watson JV (1990) Addition of fresh medium induces cell cycle and conformational changes in p53, a tumor suppressor protein. Oncogene 5: $11683-11690$

Mitsudomi T, Steinberg SM, Nau MM, Carbone D, D'Amico D, Bodner S, Oie HK, Linnoila RI, Mulshine JL, Minna JD and Gazdar A (1992) p53 gene mutations in non-small-cell lung cancer cell lines and their correlation with the presence of ras mutations and clinical features. Oncogene 7: 171-180

Moll UM, Ostermeyer AG, Haladay R, Winkfield B, Frazier F and Zambetti GP (1996) Cytoplasmic sequestration of wild-type $p 53$ protein impairs the $\mathrm{G} 1$ checkpoint after DNA damage. Mol. Cell. Biol. 16: 1126-1137

Momand J, Zambetti GP, Olson DC, George D and Levine AJ (1992) The mdm-2 oncogene product forms a complex with the p53 protein and inhibits p53mediated transactivation. Cell 69: $1237-1245$

Pinhasi-Kimhi O, Michalovitz D, Ben-Zeev A and Oren M (1986) Specific interaction between the p53 cellular tumor antigen and major heat shock proteins. Nature (London) 320: 182-185

Saylors RL, Sidransky D, Friedman HS, Bigner SH, Bigner DD, Vogelstein B and Brodeur GM (1991) Infrequent p53 gene mutations in medulloblastomas. Cancer Res. 51: 4721-4723
Seto E, Usheva A, Zambetti GP, Momand J, Horikoshi N, Weinmann R, Levine AJ and Shenk T (1992) Wild-type p53 binds to the TATA-binding protein and represses transcription. Proc. Natl. Acad. Sci. USA 89: 12028-12032

Shaulsky G, Goldfinger N, Tosky MS, Levine AJ and Rotter V (1991) Nuclear localization is essential for the activity of $p 53$ protein. Oncogene 6: 2055-2065

Sjogren S, Inganas M, Norberg T, Lindgren A, Nordgren H, Holmberg L and Bergh J (1996) The p53 gene in breast cancer: Prognistic value of complementary DNA sequencing versus immunohistochemistry. J. Natl. Cancer Ints. 88: 173-182

Spandau DF (1994) Distinct conformations of p53 are observed at different stages of keratinocyte differentiation. Oncogene 9: 1861-1868

Sturzbecher HW, Maimets T, Chumakov P, Brain R, Addison C, Simanis V, Rudge K, Philp R, Grimaldi M, Court W and Jenkins JR (1990) p53 interacts with p34 ${ }^{\text {cdc2 }}$ in mammalian cells: implications for cell cycle control and oncogenesis. Oncogene 5: $795-801$

Takahashi T, Nau MM, Chiba I, Birrer MJ, Rosenberg RK, Vinocour M, Levitt M, Pass H, Gazdar AF and Minna JD (1989) p53: a frequent target for genetic abnormalities in lung cancer. Science 246: 491-494

Thomas MD, McIntosh GG, Anderson JJ, MdKena DM, Parr AH, Johnstone R, Lennard TWJ, Horne CHW and Angus B (1997) A Novel quantitative immunoassay system for $\mathrm{p} 53$ using antibodies selected for optimum designation of $p 53$ status. J. Clin. Pathol. 50: 143-147

Varley JM, Brammar WJ, Lane DP, Swallow JE, Dolan C and Walker RA (1991) Loss of chromosome $17 \mathrm{p} 13$ sequences and mutation of p53 in human breast carcinomas. Oncogene 6: 513-521

Werness BA, Levine AJ and Howley PM (1990) Association of human papillomavirus types 16 and $18 \mathrm{E} 6$ proteins with p53. Science $248: 76-79$

Yoo J, Lee HK, Kang CS, Park WS, Lee JY and Shim SI (1997) p53 Gene mutations and p53 protein expression in human soft tissue sarcomas. Arch. Pathol. Lab. Med. 121: 395-399

Zambetti GP and Levine AJ (1993) A Comparison of the biological activities of wildtype and mutant p53. FASEB J. 7: 855-865

Zheng CF and Guan KL (1994) Cytoplasmic localization of the mitogen-activated protein kinase activator MEK. J. Biol. Chem. 269: 19947-19952 